\title{
The Phillips Curve and the Italian Lira, 1861-1998
}

\author{
Alessandra Del Boca \\ (University of Brescia) \\ Michele Fratianni \\ (Indiana University) \\ Franco Spinelli \\ (University of Brescia) \\ Carmine Trecroci ${ }^{\#}$ \\ (University of Brescia)
}

\begin{abstract}
We examine Italian inflation rates and the Phillips curve with a very long-run perspective, one that covers the entire existence of the Italian lira from political unification (1861) to the entry of Italy in the European Monetary Union (end of 1998). We first study the volatility, persistence and stationarity of the Italian inflation rate over the long run and across various exchange-rate regimes that have shaped Italian monetary history. Next, we estimate alternative Phillips equations and investigate the extent to which nonlinearities, asymmetries and structural changes characterize the inflation-output trade-off in the long run. We capture the effects of structural changes and asymmetries on the estimated parameters of the inflation-output trade-off relying partly on sub-sample estimates and partly on time-varying parameters estimated with the Kalman filter. Finally, we investigate causal relationships between inflation rates and output and extend the analysis to include the US and the UK for comparison purposes. The inference is that Italy has experienced a conventional inflation-output trade-off only during times of low inflation and stable aggregate supply.
\end{abstract}

JEL Codes: E31, E32, E5, N10.

Keywords: inflation, Phillips curve, Italian lira.

\footnotetext{
\# Corresponding author. Address: Department of Economics, University of Brescia, via San Faustino 74/b, 25122 Brescia (Italy). Tel: +39 030 2988812; Fax: +39 030 2988837; trecroci@eco.unibs.it.
} 


\section{Introduction}

After dominating the policy agenda across the 1970s and the 1980s, two decades of apparent price stability have confined the dynamics of inflationary processes to the outer limits of the macroeconomic debate. This is unsatisfactory for various reasons. First, many aspects of past inflationary processes are still unsettled, as is the issue of whether the optimal level of the inflation rate, whether zero or low. Second, inflation is not dead, as its current surge in the United States, the United Kingdom, and the euro area suggests. Third, past spells of low inflation could guide us to interpret the current state of affairs and to identify those forces that transform low rates of inflation into higher rates. This paper intends to stimulate the debate on these issues by investigating the evolving nature of the trade-off between inflation and output.

We examine Italian inflation rates and the Phillips curve with a very long-run perspective, one that covers the entire existence of the Italian lira from political unification (1861) to the entry of Italy in the European Monetary Union (end of 1998). Italy, as a case study, has two attractive features. The first is that this country has experienced higher average and more volatile inflation rates than most industrialized countries and across a variety of monetary regimes. The second is that Italy differs from anglo-saxon market structures and institutions, whereas the bulk of the literature on the Phillips curve has concentrated mainly on those countries. The long historical reach of our study appears to be particularly suitable to draw inferences among heterogeneous countries.

Methodologically, this study first examines the volatility, persistence and stationarity of the Italian inflation rate over the long run and across various exchangerate regimes that have shaped Italian monetary history (Fratianni and Spinelli, 2001a). Next, we estimate alternative Phillips equations and investigate the extent to which nonlinearities, asymmetries and structural changes characterize the inflation-output tradeoff in the long run. We capture the effects of structural changes and asymmetries on the estimated parameters of the inflation-output trade-off relying partly on sub-sample estimates and partly on time-varying parameters estimated with the Kalman filter. Finally, we investigate causal relationships between inflation rates and output and extend the analysis to include the US and the UK for comparison purposes. 
These are the main results of the paper. The rate, volatility and persistence of inflation display significant fluctuations over the entire sample. Fixed exchange rate regimes, and especially the international gold standard, are associated with lower inflation rates than more flexible forms of exchange rates. Bretton Woods stands out as the only major non-war inflationary period. Inflation persistence is higher under flexible exchange rates, especially after Bretton Woods. Non-stationarity of inflation appears to be a feature of flexible exchange rates. As to the inflation-output trade-off, we provide, among other things, estimates of a consensus model that blends the original expectationaugmented Phillips curve with the most recent stylization on persistence and price/wage rigidity (Woodford, 2003). Over the whole sample, we detect a negative relationship between inflation and output, suggesting dominance of supply-side shocks and inflation expectations. Yet, when we account for the large effects of the two world wars and post-Bretton Woods inflation, the Phillips curve exhibits the textbook positive feedback from cyclical conditions to inflation. The inference is that Italy has experienced an inflation-output trade-off only during times of low inflation and stable aggregate supply.

The paper is organized as follows. We start in Section 2 with a brief sketch of the Italian price level and its rate of change over the period from 1861 to 1998 . We then analyze in Section 3 the time series properties of the inflation rate. Section 4 is the core of the paper. There, we present and discuss estimates of a consensus Phillips curve; provide an alternative monetary specification; and examine non-linearities and timevarying parameters. In Section 5, we compare the Italian experience with that of the United States and the United Kingdom. Main conclusions are drawn in the last section.

\section{A brief sketch of prices and inflation from the Monetary History}

As a starting point, we find it useful to summarize the salient points of the behavior of the price level and its rate of change during the entire history of the lira, from political unification in 1861 to Italy's entry into the European Monetary Union (EMU) in 1998 (Fratianni and Spinelli, 2001a). We measure the price level by the logarithm of the annual price deflator of national income; see Figure $1 .{ }^{1}$ Prices are relatively stable from

\footnotetext{
${ }^{1}$ Obvious data limitations impair the study of the purchasing power of the Italian lira in the long run. However, several measures of the price level across the long time span considered in this paper have recently emerged. For instance, Spinelli and Trecroci (2008) examine time series of the implicit price
} 
1861 to the start of World War I, that is during the period characterized by the international gold standard. Upward movements in the price level occur, not surprisingly, during the two world wars and in the modern period following World War II. The years from 1927 to 1933 are instead a period of deflation.

Figure 2 displays the inflation rate computed as the first difference of the logarithm of the price deflator. It confirms visually the mean-stationary of the inflation rate during the international gold standard, the sharp accelerations imparted by the two wars, the deflation of the inter-war years, the rising inflation of the 1970s, its decline in the 1980s in sympathy with what was happening in other industrial countries, and the significant disinflation of the late 1990s. On average, Italian inflation has exceeded by five percentage points the inflation rate of the rest of the world, defined as the inflation rate of the significant reference country. ${ }^{2}$ This Italian inflation excess was contained within one percentage point during the gold standard but rose to eight percentage points in the 1970s. If we exclude the war periods, the drivers of the Italian inflation rate were fiscal and monetary impulses affecting aggregate demand against a relatively stable aggregate output supply. Overall, the fiscal impulse was dominant in the sense that it determined the course of monetary policy (Fratianni and Spinelli, 2001b).

Inflation, once started, tends to persist. This is due in part to the dynamics of inflation expectations and in part to the overhang of the monetary base that declines slowly after the end of a monetary shock. Differences in the strength of inflation expectations, driven by credible monetary policy actions, explain differences in inflation persistence. For example, monetary tightening in 1926 and 1947 was well publicized and widely believed to be permanent by the public; inflation came down quickly. On the other hand, repeated monetary tightening in the 1960s, 1970s, and 1980s was perceived to be temporary or easily reversible; inflation stuck on the high side.

Over the 138-year span of history, Italy has lived through several monetary

deflator of national income, cost of living and wholesale prices. In this paper we pick up the former, but experiments with the other indices show that most of our findings are qualitatively unaffected by the choice we make. The sample period used is 1868-1998, except in the case of the UK, where the sample starts in 1872. The pre-1950 GDP, industrial production, population and price data were obtained from Flora (1983, 1987) and Mitchell (1992, 1993), whilst data on exchange rates, fiscal variables and the money supply are compiled by Fratianni and Spinelli (2001a) using a variety of historical sources. The data for the post-1950 period was checked for consistency using standard sources (IFS, OECD).

\footnotetext{
${ }^{2}$ The reference country is France up to World War I, the United Kingdom in the inter-war period, and the
} United States after World War II. 
regimes: it has swung from the gold standard to inconvertible fiat money; alternated periods of fixed exchange rates with periods of flexible rates; and experimented alternatively with interest rate, total domestic credit, monetary base, and inflation rate targeting. The fixed exchange rate regime was often adopted to signal the country's determination to a course of deflation or disinflation, but just as often created unsustainable conflicts with other goals of economic policy and, hence, was not a credible pre-commitment device for deflation or disinflation. It is worth pointing out that the successful disinflation of the nineties, which made it possible for Italy to join EMU, instead, was the result of a tough-minded inflation rate targeting and was accompanied by stable output growth.

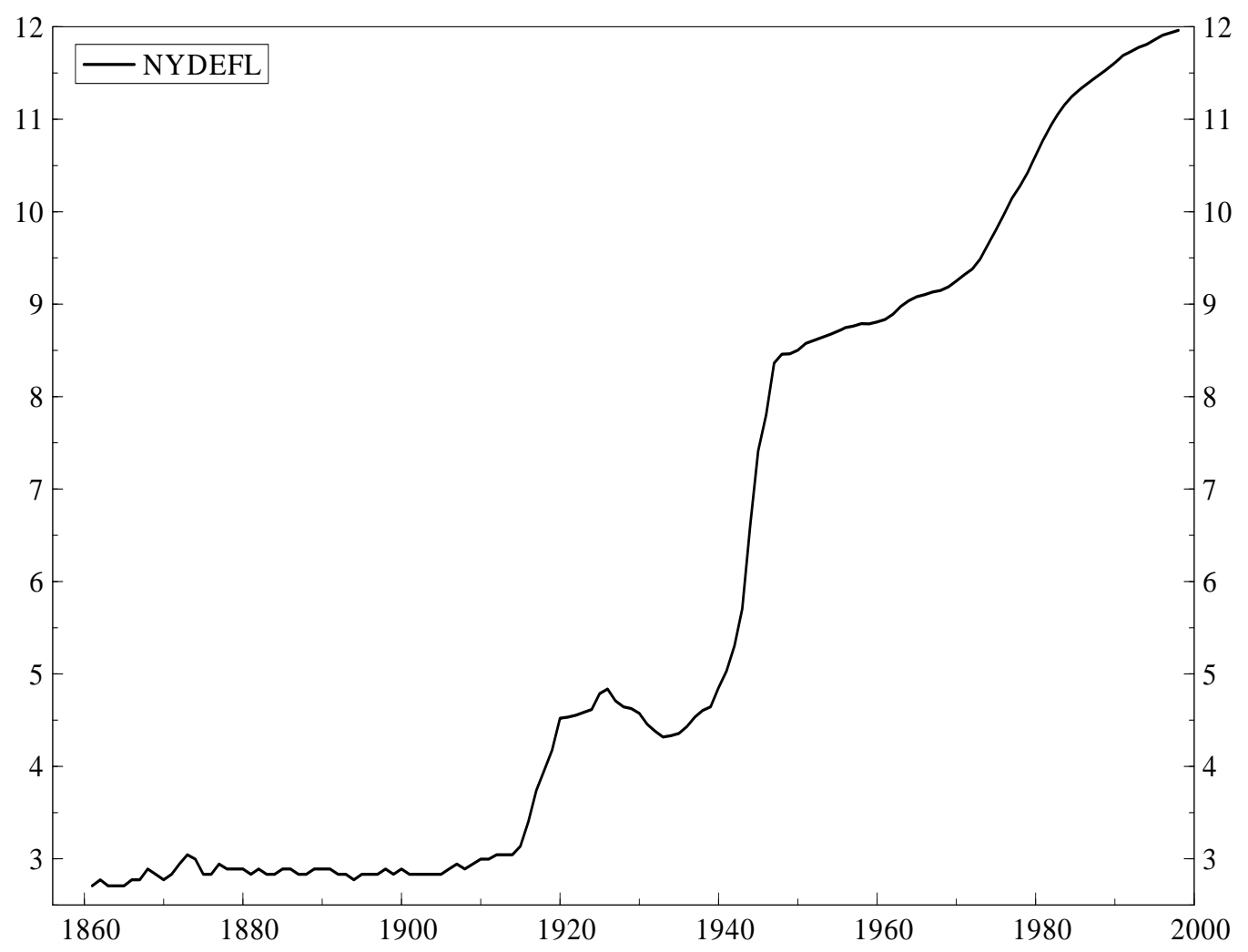

Figure 1: The log of the price deflator of Italian national income, 1861-1998 


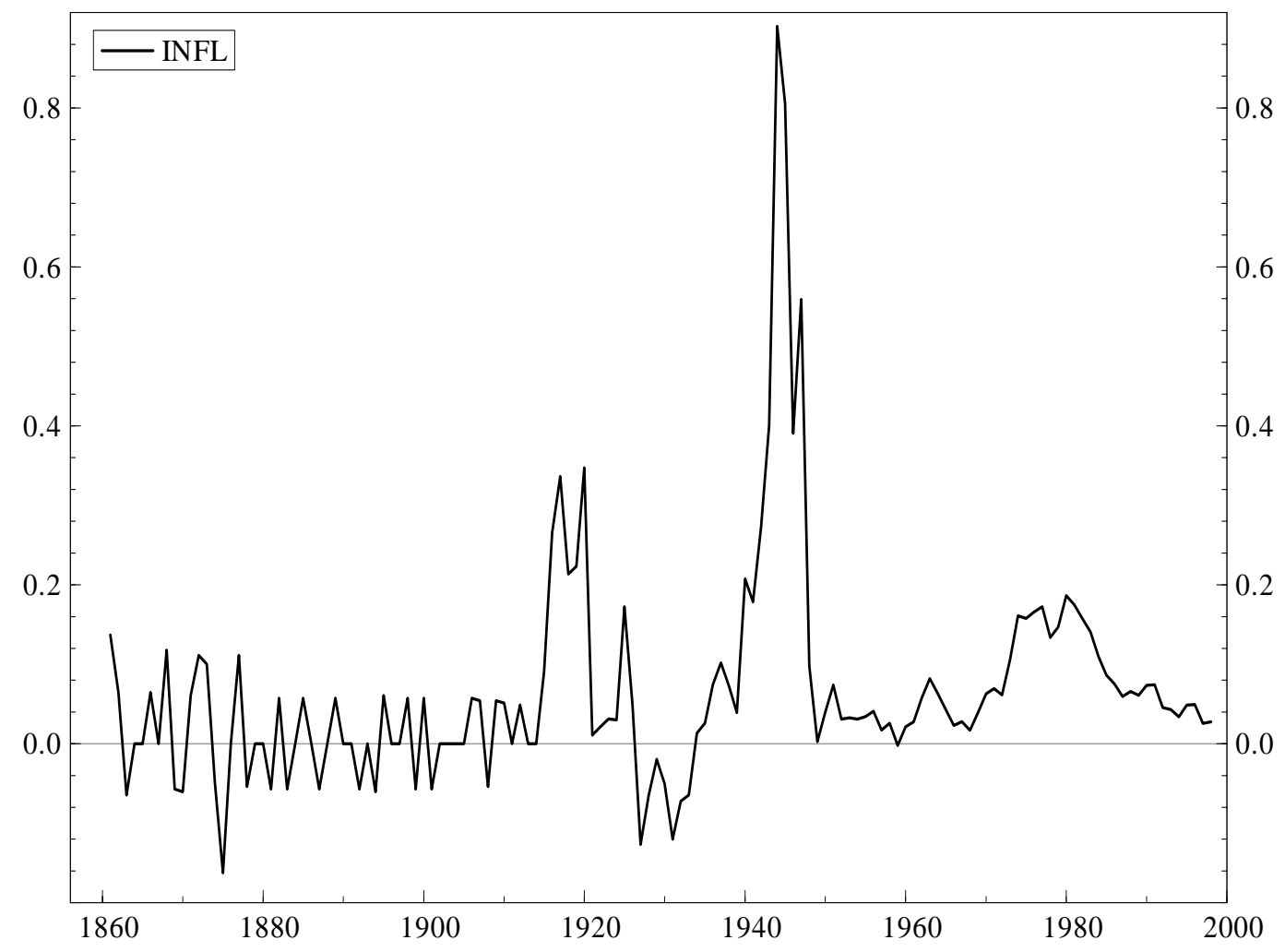

Figure 2: The log change of the price deflator of Italian national income, 1861-1998

\section{Statistical analysis of the Italian inflation process}

To capture the evolution of the statistical properties of the Italian inflationary processes, we focus on both the whole span 1861-1998 and some sub samples defined by the different monetary and exchange-rate regimes Italy adopted over the long period under observation. In particular, we consider the following partition, put forward by Fratianni and Spinelli (2001a):

1) 1861-1913: international gold standard and fixed exchange rates;

2) 1914-1949: world wars and interwar years, mainly with flexible exchange rates;

2.1) 1920-1936: interwar years, with spells of both fixed and flexible rates;

3) 1950-1973: Bretton Woods system, hence fixed exchange rates;

4) 1974-1998: fixed but adjustable peg. 
Table 1 displays average inflation rates $(\mu)$, their standard deviations $(\sigma)$ and variation coefficients ( $c v=\sigma / \mu$ ) for the whole sample and the five sub periods.

\begin{tabular}{|c|c|c|c|}
\hline \hline \multirow{2}{*}{ SAMPLE } & \multicolumn{3}{|c|}{$e_{1}=1375.2^{* *} ; e_{2}=261.79 * *$} \\
\cline { 2 - 4 } & $\mu$ & $\sigma$ & $\mathbf{c v}$ \\
\hline $\mathbf{1 8 6 1 - 1 9 9 8}$ & 6.805 & 13.934 & 2.048 \\
\hline $\mathbf{1 8 6 1 - 1 9 1 3}$ & 0.647 & 5.801 & 8.966 \\
\hline $\mathbf{1 9 1 4 - 1 9 4 9}$ & 15.049 & 23.252 & 1.545 \\
\hline $\mathbf{1 9 2 0 - 1 9 3 6}$ & 1.508 & 10.976 & 7.279 \\
\hline $\mathbf{1 9 5 0 - 1 9 7 3}$ & 4.269 & 2.423 & 0.568 \\
\hline $\mathbf{1 9 7 4 - 1 9 9 8}$ & 9.902 & 5.334 & 0.539 \\
\hline \hline
\end{tabular}

Table 1: Italian inflation rate, 1861-1998. Average $(\mu)$, standard deviation $(\sigma)$, coefficient of variation $(c v)$, and normality test. ' $* *$ ' indicates rejection of the null with a $99 \%$ confidence interval.

Barring World War II, the period with the highest average inflation was the postBretton Woods era of fixed but adjustable peg, while the international gold standard and Bretton Woods periods had the lowest inflation. Inflation volatility, as measured by the its standard deviation, was highest in the 1914-1949 sub sample, but adjusting this measure for its mean reveals greater variability during the international gold standard and lower variability in the last half of the $20^{\text {th }}$ century. Overall, the inflation rate, on average, is lower under fixed exchange rates than under flexible exchange rates. Amongst the two experiences with fixed exchange rates, the Bretton Woods years had a much higher inflation rate, although less volatile, than the gold standard years. There is, however, ample time variation in the mean and standard deviation, which invites to a deeper examination of inflation's stationarity properties.

Table 1 also shows the results of Jarque and Bera (1987) $\left(e_{1}\right)$ and Doornik and Hansen (1994) $\left(e_{2}\right)$ tests for normality. Essentially, these tests evaluate whether asymmetry and kurtosis of the series correspond to those of a normal distribution. ${ }^{3}$

\footnotetext{
${ }^{3}$ While the Jarque and Bera's test has low power in small samples, Doornik and Hansen's test adjusts for this bias.
} 
Table 1 shows results for the whole sample: there is clear evidence against the null of normality. To evaluate persistence, we compute the autocorrelation function (ACF) up to the 10th lag. Figure 3 plots the function computed over the whole sample. The first lags have large coefficients, while negative values emerge only after 8-9 lags; we conclude that Italian inflation was highly persistent. Figure 4 displays the correlogram for the four main sub-periods, ${ }^{4}$ and confirms that persistence was higher with flexible exchange rates and reached a maximum after the demise of the Bretton Woods system.

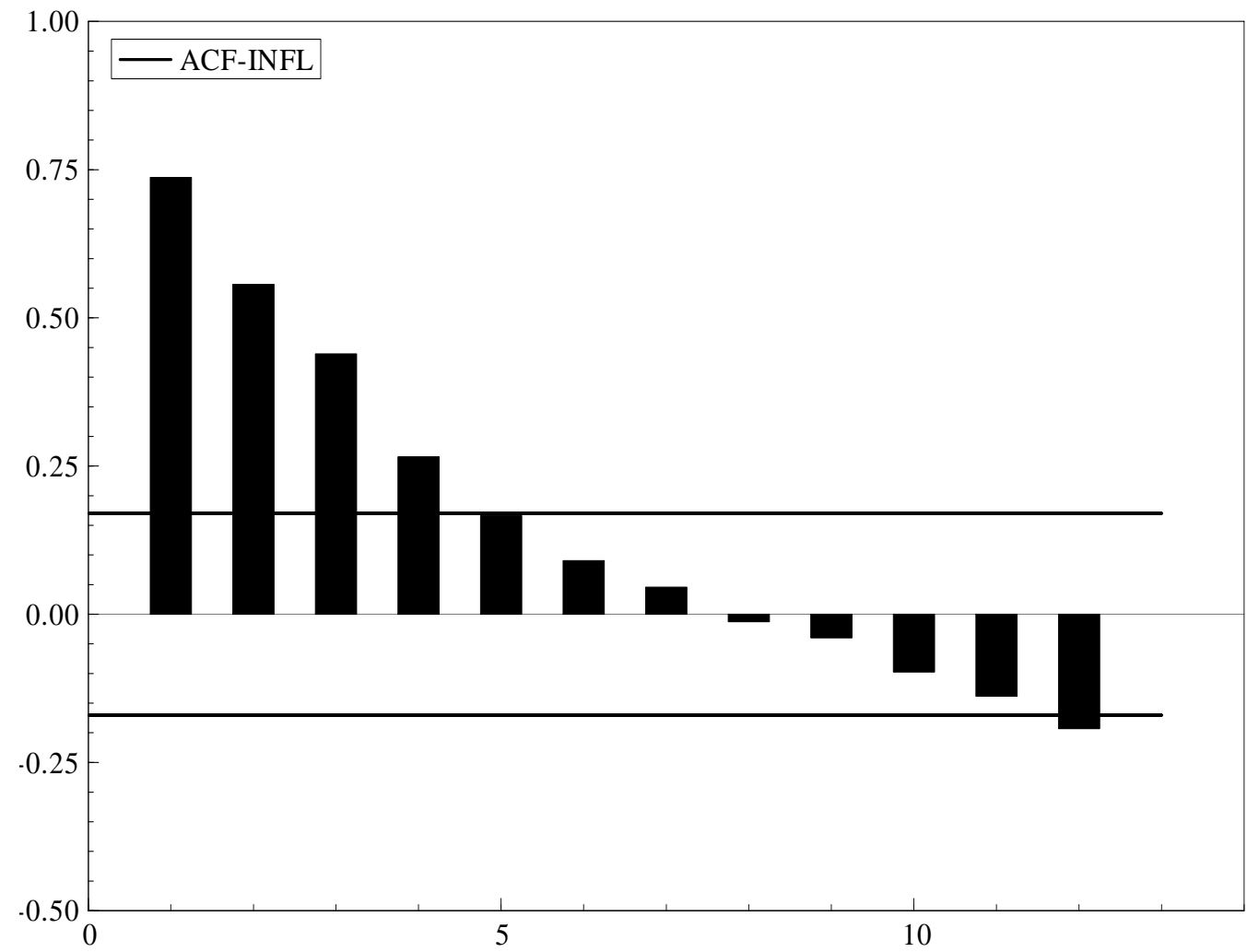

Figure 3: Autocorrelation function of the Italian inflation rate, 1861-1998. Horizontal lines represent \pm 2 standard deviations from estimated autocorrelations, assuming the population value is zero.

\footnotetext{
${ }^{4}$ Given the limited number of its observations, we do not include results for the 1920-1936 sub sample.
} 

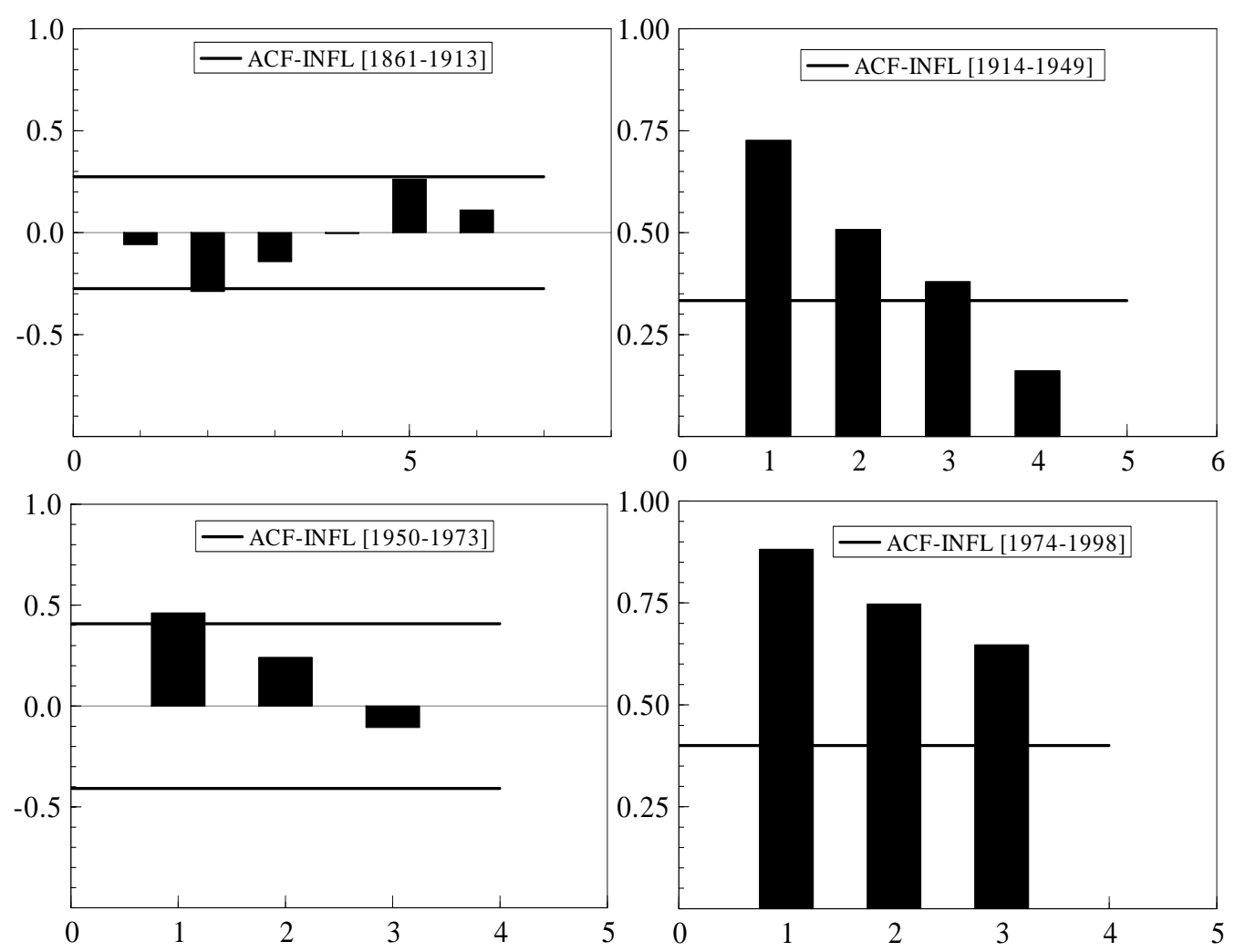

Figure 4: Autocorrelation function of the Italian inflation rate, various subsamples. Horizontal lines represent \pm 2 standard deviations from estimated autocorrelations, assuming the population value is zero.

Finally, we investigate the stationarity of the inflation process. To this end, we employ the Augmented Dickey-Fuller (ADF) test, which is implicit in the evaluation of the t-statistic $t$ of the $\hat{\beta}$ coefficient in:

$$
\Delta \pi_{t}=\alpha+\mu \tau+\beta \pi_{t-1}+\sum_{i=1}^{n} \gamma_{i} \Delta \pi_{t-i}+u_{t},
$$

where $\tau$ is a deterministic trend. A significant statistic would imply rejection of the null hypothesis of unit root $\left(H_{0}: \beta=0\right)$ and therefore stationarity of the inflation rate.

Table 2 presents results for the whole sample and the four main sub-periods. We included t-values of the $\beta$ coefficient for both the model with a constant and the model with a constant and a trend, each estimated with $n=3.5$

\footnotetext{
${ }^{5}$ The critical values for this procedure depend on the inclusion of the constant or of the constant and a trend term. The critical values we employ are those of MacKinnon (1991). A statistic significant at the $5 \%$ is identified by $*$, at the $1 \%$ by **.
} 


\begin{tabular}{|l|c|c|c|c|c|c|c|c|}
\hline \hline INFL & \multicolumn{4}{|c|}{ Constant } & \multicolumn{4}{c|}{ Constant and trend } \\
\hline SAMPLE & $\boldsymbol{i = 0}$ & $\boldsymbol{i}=\mathbf{1}$ & $\boldsymbol{i = 2}$ & $\boldsymbol{i = 3}$ & $\boldsymbol{i}=\mathbf{0}$ & $\boldsymbol{i = 1}$ & $\boldsymbol{i = 2}$ & $\boldsymbol{i = 3}$ \\
\hline $\mathbf{1 8 6 1 - 1 9 9 8}$ & $-4.535^{* *}$ & $-4.095^{* *}$ & $-3.732^{* *}$ & $-4.114^{* *}$ & $-4.656^{* *}$ & $-4.219^{* *}$ & $-3.853^{*}$ & $-4.285^{* *}$ \\
\hline $\mathbf{1 8 6 1 - 1 9 1 3}$ & $-7.364^{* *}$ & $-6.683^{* *}$ & $-6.497^{* *}$ & $-5.662^{* *}$ & $-7.315^{* *}$ & $-6.671^{* *}$ & $-6.512^{* *}$ & $-5.729 * *$ \\
\hline $\mathbf{1 9 1 4 - 1 9 4 9}$ & -2.264 & -2.211 & -2.082 & -2.673 & -2.209 & -2.171 & -2.058 & -2.684 \\
\hline $\mathbf{1 9 5 0 - 1 9 7 3}$ & -2.004 & -1.571 & -1.406 & -1.154 & -2.292 & -1.823 & -1.807 & -1.548 \\
\hline $\mathbf{1 9 7 4 - 1 9 9 8}$ & -0.4841 & -0.9693 & -0.6881 & -1.207 & $-3.719^{*}$ & $-3.690^{*}$ & -3.374 & -3.582 \\
\hline \hline
\end{tabular}

Table 2: ADF test of the Italian inflation rate, various sub-samples. '**' indicates rejection of the null with a $99 \%$ confidence interval.

The results of the ADF test can be summarized as follows:

a) Over the whole sample, inflation appears to be a stationary process: the null of a unit root can be rejected in both models with a 1\% significance level;

b) The same applies to the gold standard years;

c) On the contrary, the period 1914-1949 is unambiguously characterized by nonstationarity; and

d) For the Bretton Woods years and afterwards, overall results support nonstationarity.

These findings suggest that fixed exchange rates tend to be associated with stationary inflation, whilst flexible rates are best characterized by non-stationary inflation. However, the nature and frequency of the structural changes cannot be determined through unit root tests. Moreover, the ADF test has low power in small samples and variables containing MA components (Maddala and Kim, 1998). This suggests focusing on structural breaks rather than on the unit root properties of the series and to study the structural changes of the inflationary process jointly with output dynamics, within the context of the Phillips curve.

\section{Italian inflation and output in the long run}

In the light of the above results, it appears crucial to distinguish the temporary components of the inflation process from its more permanent, long-term component. Various methods are available. It is common to extract trend inflation through the application of Hodrick-Prescott (HP), linear or band-pass filters. Alternatively, results from market surveys or measures extracted from inflation swaps or bond-based breakeven inflation rates are available, but only for relatively short and recent samples of 
data. In this paper, we employ the Structural Time Series (STS) approach proposed by Harvey (1989) to generate a series for trend inflation. The procedure amounts to decomposing the original series into trend, recursive stochastic cycles, and irregular components that vary over time ${ }^{6}$. This way, we extract time-varying measures of expected inflation that for each observation rely only on information available up to the point of estimation. This modelling approach applies a Kalman-filter estimation procedure, in line with a plausible learning process for both the central bank and private agents. Other procedures, like using alternative filtering methods or polynomial trends, did not yield significantly better fit for our model.

Figure 5 plots the estimated Kalman-filter-based trend along with that of a trend computed using the more conventional Hodrick-Prescott filter. We will use them in turn in our subsequent estimates.

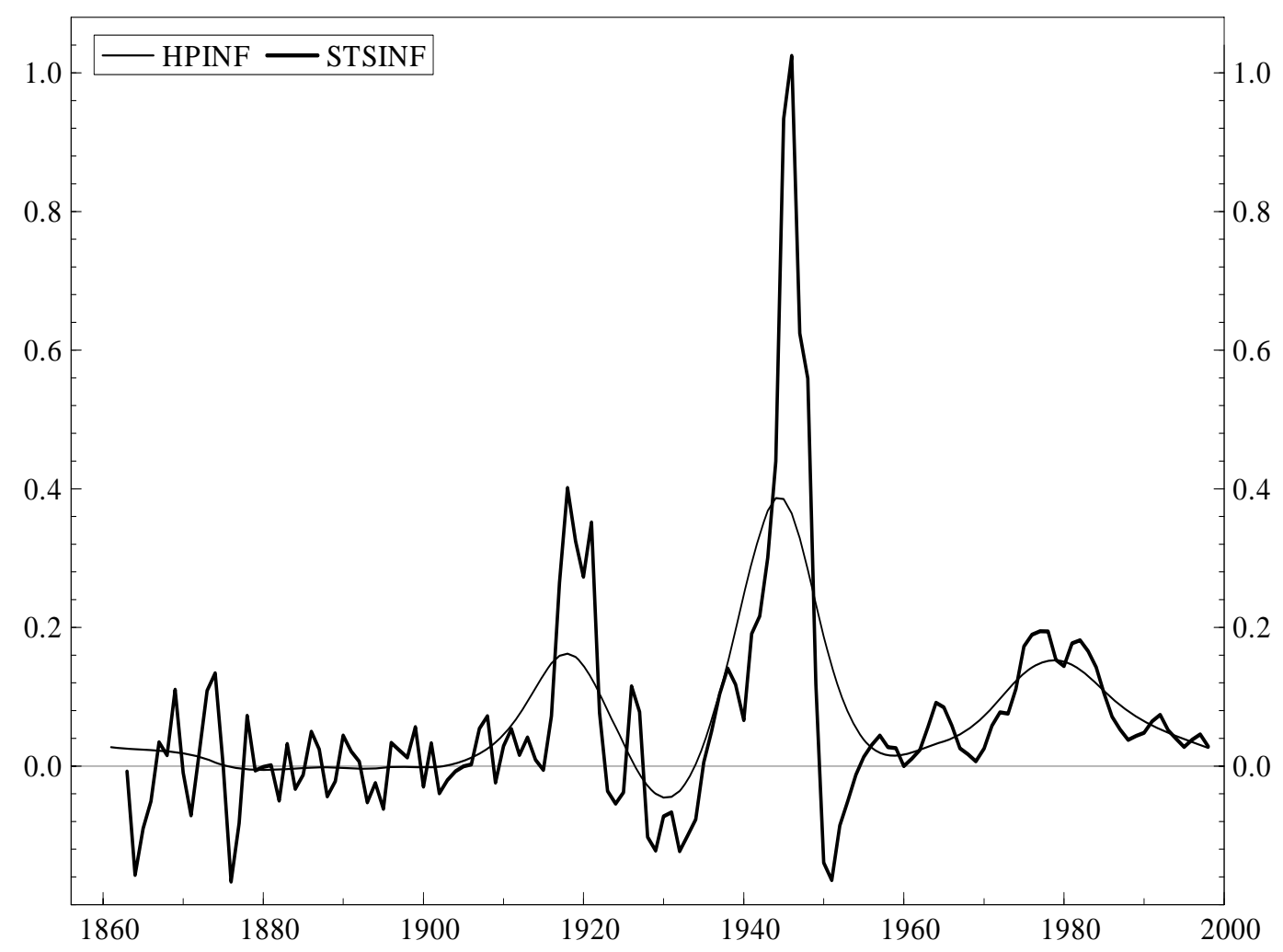

Figure 5: Trend Italian inflation rate, 1861-1998. The two measures of trend inflation are Hodrick-Prescott (HPINF) and Kalman filter (STSINF).

\footnotetext{
${ }^{6}$ For more details, see Hamilton (1994) and Canova (2007).
} 
Figure 6 plots actual inflation and both the HP and STS measures of expected inflation for the most recent part of the sample, 1949-98. The third notable inflation process in the sample appears to originate already in the early 1960s, peak in 1980-82, and get back to moderate levels only at the end of the sample.

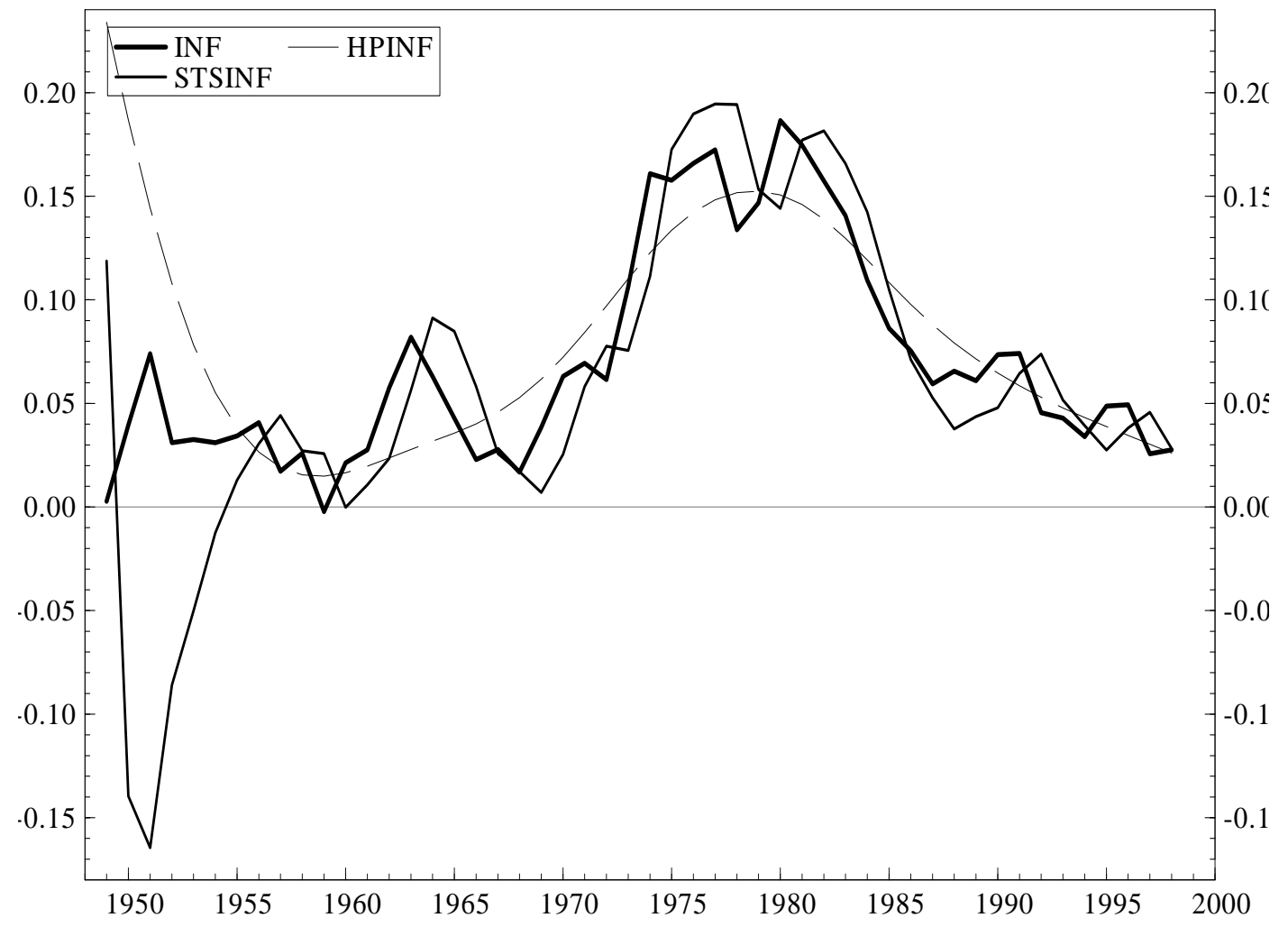

Figure 6: Trend Italian inflation rate, 1949-1998. The two measures of trend inflation are Hodrick-Prescott (HPINF) and Kalman filter (STSINF).

\section{New Keynesian Phillips curve}

We now examine the joint behavior of long-term output and the inflation rate with the intent of understanding the cyclical and structural determinants of the inflationary process. Our reference framework is a consensus model of inflation and output that blends the original expectation-augmented Phillips curve (Phelps, 1967; Friedman, 1968) with the most recent stylizations on persistence and price/wage rigidity (Woodford, 2003). We shall refer to this framework as the New Keynesian Phillips curve (NKPC), which has the following reduced-form representation of the relationship between inflation and output: 


$$
\pi_{t}=\gamma\left(y_{t}-y_{t}^{*}\right)+E_{t-1} \pi_{t}
$$

where $y_{t}-y_{t}^{*}$ denotes the output gap, that is the difference between the current level of output and its NAIRU or natural level, and $E_{t-1} \pi_{t}$ the expected inflation rate, conditional on last period's information. The dependence of current inflation on last period's expectations comes from the application of rational expectations to a structural model with partial price rigidities. This implies that (i) unexpected changes in aggregate demand affect both inflation and output and (ii) the stickier the prices, the lower $\gamma$, that is the slope of the Phillips curve.

The literature often discusses the alternative equation (2):

$$
\pi_{t}=\gamma\left(y_{t}-y_{t}^{*}\right)+\beta E_{t} \pi_{t+1}
$$

which links shifts of the curve to changes in current conditional expectations of future inflation. Theoretically, the difference between (1) and (2) is noticeable; in practice much less so, given that expected inflation is serially correlated. For this reason, our estimates are based on the following encompassing model (Woodford, 2003):

$$
\pi_{t}=\beta E_{t} \pi_{t+1}+\omega \pi_{t-1}+\gamma\left(y_{t}-y_{t}^{*}\right)+\varepsilon_{t}
$$

To measure the output gap, we employ again the STS approach. We fit a univariate model for real GDP, and extract time-varying measures of potential output relying, for each observation, only on information available up to the point of estimation. As a robustness check, we also employ three alternative measures or techniques: a measure of output gap provided by the OECD; HP- and band-pass filters; and the log change in the index of industrial production. As shown by the results below, often we found much stability in the estimates of the Phillips curve using alternative indicators/techniques.

Figure 7 displays a scatter plot of the inflation rate and our two measures of the output gap over the whole sample, along with a regression line. In contrast with the conventional Phillips relationship, a negative association emerges between inflation and 
deviations of output from potential output. This apparently puzzling finding spans over a very long sample and three important inflationary episodes with many potential structural breaks. It follows that our estimation should be performed over shorter subsamples as well.
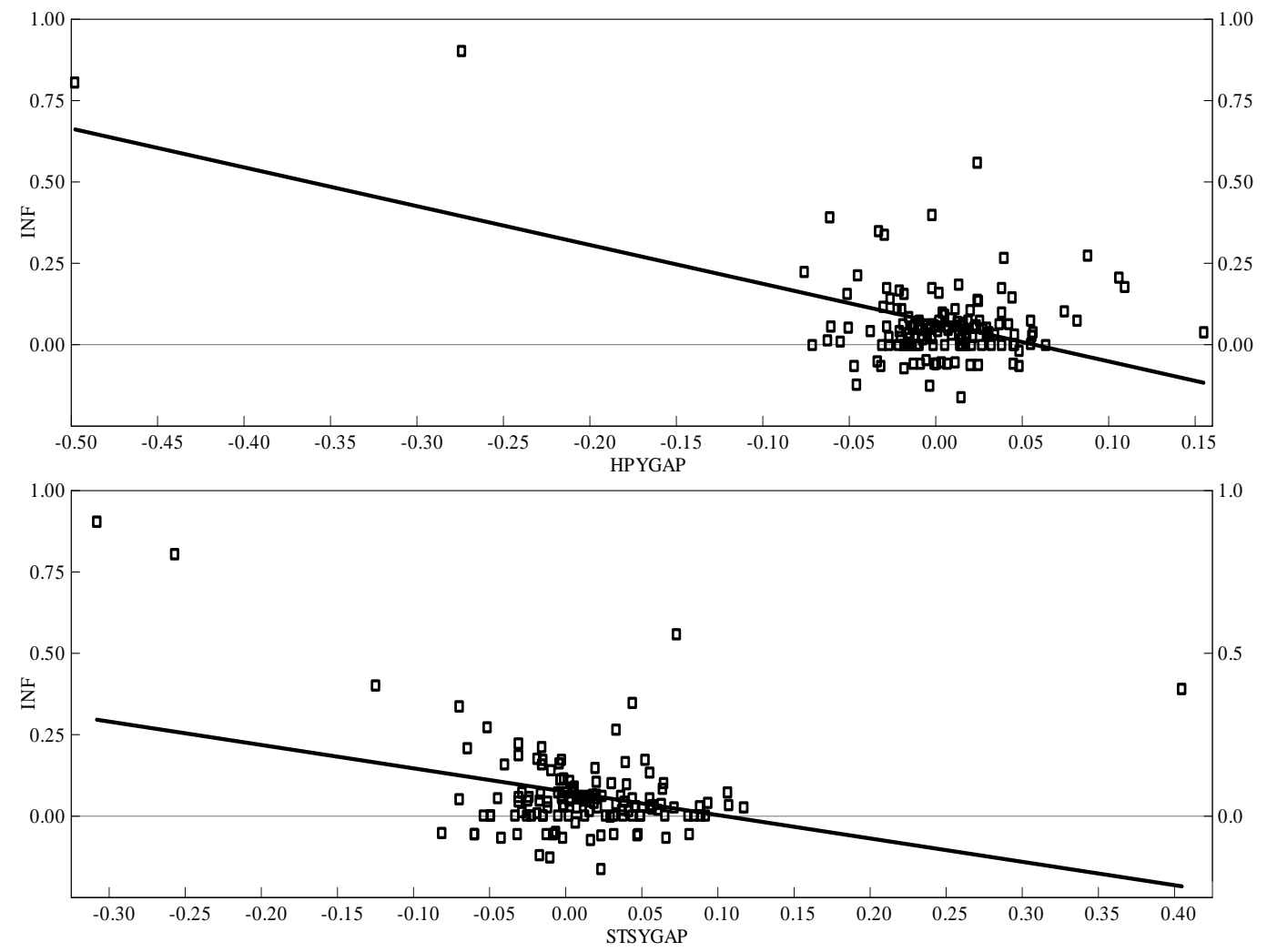

Figure 7: The relationship between Italian inflation and output gap, 1861-1998. Inflation (INF) and Hodrick-Prescott (HPYGAP) and Kalman-filter (STSYGAP) measures of the output gap.

\section{Sub-sample estimates}

We proceed as follows. First, we estimate equation (3), using OLS, over the entire period but after removing the observations relative to the world wars. ${ }^{7}$ For the output gap, we use either the HP or STS definitions or the log change in industrial production $\left(D I P_{t}\right)$. The estimates are shown in equations (4)-(6) below ( $t$-values in parentheses):

\footnotetext{
${ }^{7}$ We also computed estimates of a specification that included dummy variables for the world wars amongst the regressors. However, we prefer to present estimates obtained over a sample from which war observations are removed. Full results are anyway available upon request.
} 


$$
\begin{aligned}
\pi_{t}= & 0.541 E_{t} \pi_{t+1}+0.268 \pi_{t-1}-0.255\left(y_{t}-y_{t}^{*}\right)^{H P}+\hat{\varepsilon}_{t} \\
\pi_{t}= & 0.509 E_{t} \pi_{t+1}+0.275 \pi_{t-1}-0.092\left(y_{t}-y_{t}^{*}\right)^{S T S}+\hat{\varepsilon}_{t} \\
& (5.98) \\
\pi_{t}= & 0.488 E_{t} \pi_{t+1}+0.298 \pi_{t-1}+0.001 D I P_{t}+\hat{\varepsilon}_{t}
\end{aligned}
$$

Overall, real activity turns out to have almost no influence on inflation dynamics: using the HP-based definition, the output gap becomes marginally significant, although again with a negative sign, only under the H-P definition. Industrial production is not statistically significant. On the contrary, forward-looking inflation expectations and lagged inflation are significant, and remain so over variously defined sub-samples. The likely reasons of these findings is that the data are dominated by recurrent periods of large output and inflation shocks. Figure 8 shows scatter plots over the estimation sample after eliminating the years 1973-1984, which characterize the deepest non-war inflationary (and stagflationary) process. A positive inflation-output relationship finally emerges, albeit a weak one. It confirms that the canonical output-inflation trade-off is present when large real or monetary shocks are removed from the data. ${ }^{8}$

\footnotetext{
${ }^{8}$ Results are very similar when the change in industrial production is used.
} 

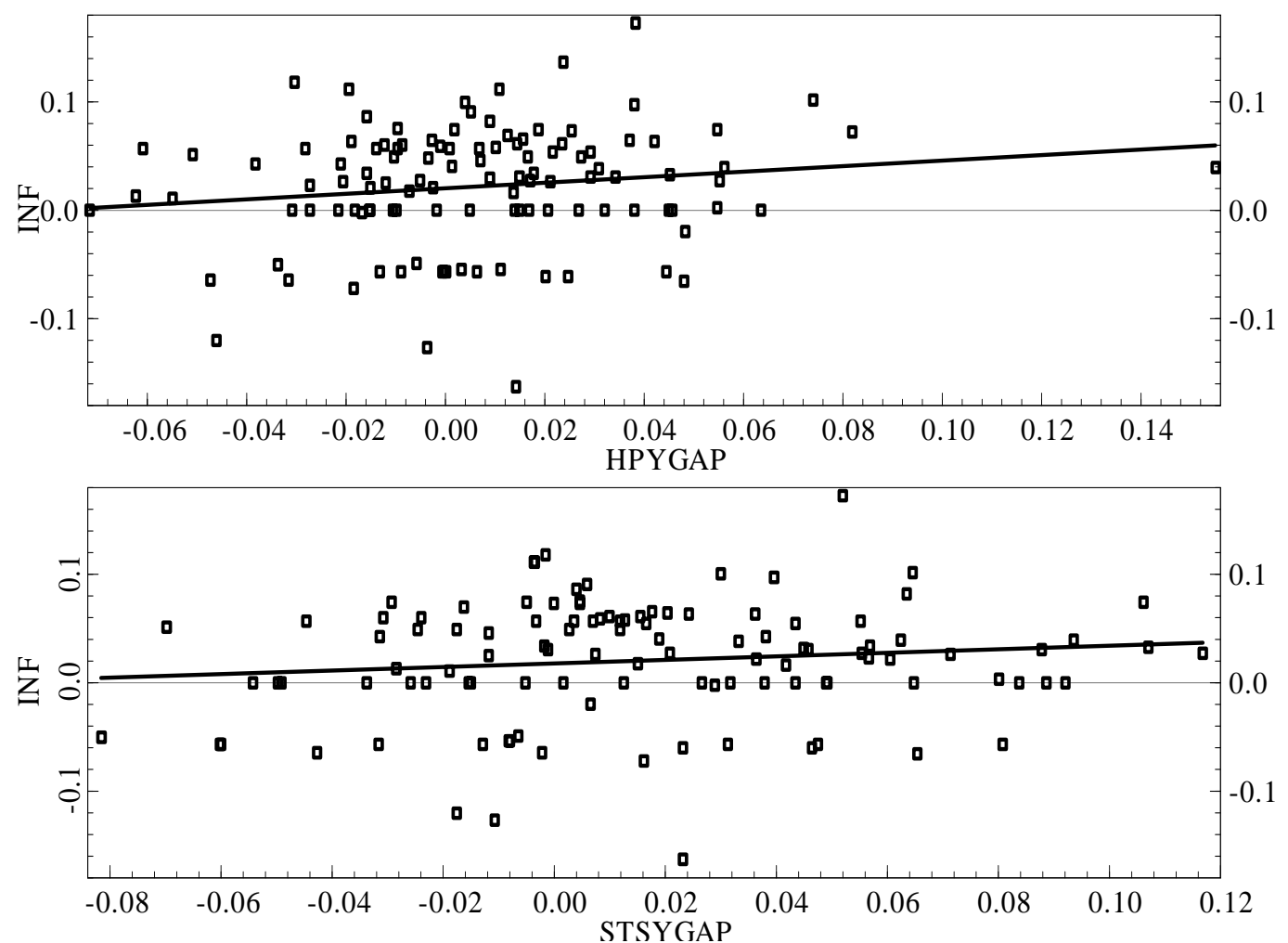

Figure 8, The relationship between Italian inflation and output gap, 1861-1915, 1921-1939, 1948-1972, 1985-1998. Inflation (INF) and Hodrick-Prescott (HPYGAP) and Kalman-filter (STSYGAP) measures of the output gap.

$\underline{\text { Alternative specification and robustness checks }}$

We complement the evidence on the NKPC by performing a classical test of the quantity theory, namely that inflation responds to money growth. We begin by recalling the essential point made by Lucas (1980) that the quantity relation might not hold with high frequency data and in the short run, ${ }^{9}$ Our long-term perspective is the ideal context in which to carry out such an experiment. We start, in the spirit of Lucas, by simply plotting the inflation rate against the annual growth rate of the broad money stock; see Figure 9. The positive correlation between the two variables is so tight that cannot be dismissed.

\footnotetext{
${ }^{9}$ For this reason, Lucas (1980) employed gradually stronger filtering to make the relation emerge with US data. Results obtained using filtered data show that inflation moves roughly one-for-one with money growth.
} 


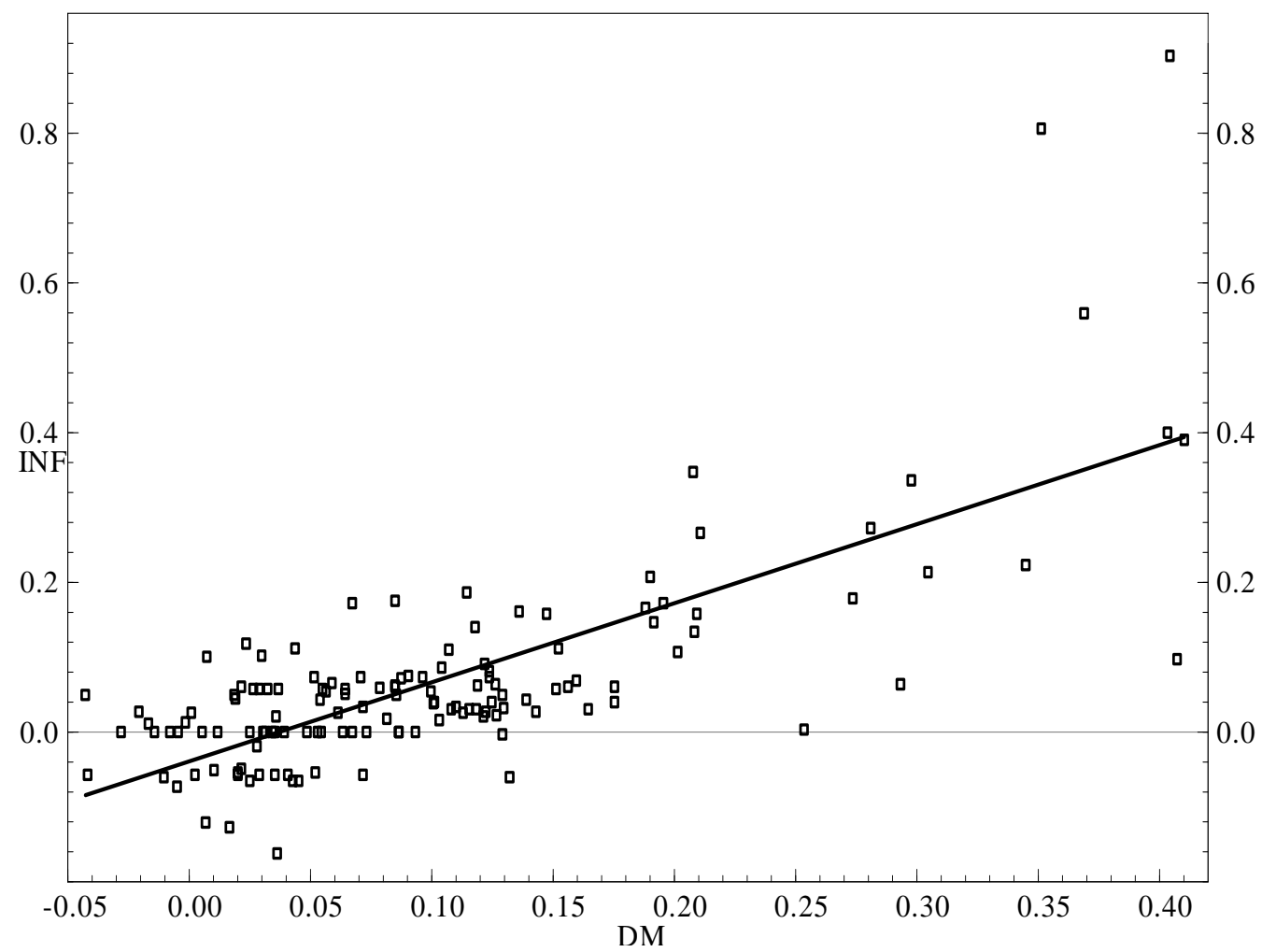

Figure 9: The relationship between Italian inflation rate (INF) and the growth rate of the broad money stock (DM), 1861-1998.

Next, we re-estimate the inflation model of equation (3), but add a variant in which money growth replaces the output gap. To account for the extreme outliers of World War II, we also include a dummy variable (WDum) that takes value 1 for years 1944-45 and 0 elsewhere. The re-estimated equation (3) with WDum and the money variant are reported below:

$$
\begin{aligned}
\pi_{t}= & 0.858 E_{t} \pi_{t+1}+0.118 \pi_{t-1}-0.405\left(y_{t}-y_{t}^{*}\right)^{H P}+0.302 \text { WDum }_{t}+\hat{\varepsilon}_{t} \\
& \quad(7.91)
\end{aligned}
$$




$$
\begin{aligned}
& \pi_{t}=0.489 E_{t} \pi_{t+1}+0.115 \pi_{t-1}+0.387 \Delta m_{t}+0.469 W_{D D m}+\hat{\varepsilon}_{t} \\
& \quad(4.02) \\
& R^{2}=0.81
\end{aligned}
$$

Inflation is highly correlated with money growth, whereas it remains negatively and significantly correlated to the output gap even after accounting for the decoupling of money and income during the war years. Furthermore, model (8) achieves a slightly better fit than (7). Overall, these results confirm the monetary roots of inflation and are in accord with evidence gathered, over shorter periods, by Fratianni (1978) and Fratianni and Spinelli (2001a).

As a further check, we add the log change in the index of import prices $\left(\pi_{t}^{*}\right)$ to the baseline specification, in order to capture the influence of external inflation on domestic prices:

$$
\begin{aligned}
\pi_{t}= & 0.43 E_{t} \pi_{t+1}+0.096 \pi_{t-1}-0.394\left(y_{t}-y_{t}^{*}\right)^{H P}-0.054 \text { WDum }_{t}+0.511 \pi_{t}^{*}+\hat{\varepsilon}_{t}, \\
& (5.42)
\end{aligned}
$$

In light of the fact that Italy is a small open economy, it is not surprising that the coefficient on import prices is both statistically highly significant and economically relevant. Furthermore, its insertion raises the statistical significance of all other regressors and improves the overall fit of the model. It should be noted, however, that import prices can change either as a result of changes of relative prices or as a result of changes in the nominal exchange rate. We cannot directly distinguish between the two sources of changes but we hypothesize that, given the substantial stability in the magnitude of all other coefficients, nominal exchange rate shifts are likely to drive most of the correlation between domestic inflation and import prices.

\section{$\underline{\text { Non-linearities and time-varying parameters }}$}

Our final econometric exercise tests for the presence of non-linearities and/or asymmetries in the long-run Phillips curve. Starting with Phillips (1958) himself, a large body of literature has investigated the presence of convexities in the transmission from 
the output gap to inflation. According to this idea, an excess demand has a greater effect on inflation than an equivalent amount of excess supply. To provide an indicative answer to this question, we use a series of residual-based tests designed to verify whether non-linear effects are present (Granger and Terasvirta, 1993). Retrieving the fitted residuals from specifications (7) and (8), we estimate the following auxiliary regression: ${ }^{10}$

$$
\hat{\varepsilon}_{t}=\beta_{0}^{\prime} x_{t}+\beta_{1}^{\prime} x_{t} z_{t}+\beta_{2}^{\prime} x_{t}\left(z_{t}\right)^{2}+\beta_{3}^{\prime} x_{t}\left(z_{t}\right)^{3} \text {, }
$$

where $x_{t}$ is the vector of regressors in the Phillips curve and $z_{t}$ is any 'transition' variable, whether in the model or outside, that may be a source of nonlinear behavior. In what follows, we perform these tests primarily against the output gap and money growth. While we do not know the actual nature of the convexities, we hypothesize that the two transition variables capture the bulk of monetary and real factors. The power of the tests is high against most parametric approaches of nonlinearity. Results, shown in Table 3, support the presence of the inflation rate driven by the determinants of the Phillips curve.

\begin{tabular}{|l|l|l|l|}
\hline \hline \multicolumn{2}{|l|}{ SAMPLE: 1861-1998 } & $H_{0}: \beta_{1}=0$ & $H_{0}: \beta_{2}=\beta_{3}=0$ \\
\hline \multirow{3}{*}{ Model (7) } & $z_{t}=\left(y_{t}-y_{t}^{*}\right)$ & $\begin{array}{l}4.8790 * * \\
27.841^{* *}\end{array}$ & $\begin{array}{l}13.968 * * \\
38.454 * *\end{array}$ \\
& $z_{t}=\Delta m_{t}$ & & \\
\hline \multirow{3}{*}{ Model (8) } & $z_{t}=\left(y_{t}-y_{t}^{*}\right)$ & $6.5323^{* *}$ & $23.716^{* *}$ \\
& $z_{t}=\Delta m_{t}$ & $12.822^{* *}$ & $60.071^{* *}$ \\
\hline \hline
\end{tabular}

Table 3: Granger-Terasvirta tests for non-linear inflation responses. $H_{0}: \beta_{1}=0$ test is distributed as an $\mathrm{F}(4,120)$ variate. $H_{0}: \beta_{2}=\beta_{3}=0$ test is distributed as a $\mathrm{F}(8$, $120)$ variate. “*, **, ***” indicate that the null hypothesis of a zero restriction is rejected, respectively, at the $10 \%, 5 \%$ or $1 \%$ level.

\footnotetext{
${ }^{10}$ Results based on residuals from the other specifications are broadly consistent with those we present here and are available upon request.
} 
All our findings are consistent with the literature on the stability of the Phillips curve, showing breaks in the estimated coefficients (Bai and Perron, 2003). These changes can be attributed to shifts in the actual conduct of monetary policies, in the collective attitude towards the costs of inflation, or more generally in the monetary regime (Cecchetti et al., 2007; Kim and Nelson, 2006). Our findings for Italy and the evidence concerning other economies amply justify the use of a full-fledged timevarying parameter (TVP) approach. ${ }^{11}$ TVP helps to identify conditional long-run inflation-output trade-off and the causal links between observed institutional or behavioral changes and structural shifts in parameters. We therefore compute additional estimates that explicitly allow for time variation in the parameters of the Phillips curve. These estimates describe the temporal evolution of the Phillips curve's coefficients.

We represent the model in a general state-space form (Harvey, 1989; Kim and

Nelson, 1999):

$$
\begin{aligned}
& \pi_{t}=c_{t}+x_{t}^{\prime} b_{t}+e_{t} \\
& b_{t+1}=d+T^{\prime} b_{t}+z_{t+1}
\end{aligned}
$$

where

$$
e_{t} \approx N\left(0, \sigma^{2}\right), z_{t} \approx N(0, Q), b_{0} \approx N\left(a_{0}, \Sigma_{0}\right),
$$

with $x_{t}$ defining the explanatory variables.

The first equation in (11) is the measurement or observation equation, where the parameter vector $b_{t}$ (representing the state variables) is time sensitive. The second equation is the transition equation describing the temporal evolution of $b_{t} \cdot{ }^{12}$ In sum, TVP involves forecasting the optimal state vector in each period, based on information available up to the previous period. ${ }^{13}$ Thus, we can compute filtered estimates of the parameters and residuals for each observation in the sample and account for the

\footnotetext{
${ }^{11}$ Alternatively, one could insert variously defined time trends in the model. We believe that the approach we employed simply yields much richer evidence about the extent of time variation, especially as far as aggregate demand and inflation expectations are concerned.

${ }^{12}$ We follow the prior distribution proposed by Doan et al. (1984), which assume that changes in the endogenous variable modelled are so difficult to forecast that in the AR(1) process of the unobserved state vector the coefficient on its lagged value is likely to be near unity, while all other coefficients are assumed to be near zero. The prior distribution is independent across coefficients, so that the MSE of the state vector is a diagonal matrix. Measurement errors and the disturbances to transition equations are assumed to be serially and mutually independent.

${ }^{13}$ Under the normality and independence assumptions about the disturbances, the computation of the state vector is obtained via application of the Kalman filter.
} 
potential temporal variation of the underlying structural parameters. The objective is to capture major shifts, which are extremely likely in the long historical span of our dataset.

Figure 10 plots the times series of the estimated coefficient $\gamma_{t}$ of equation (3), that is, the sensitivity of current inflation to changes in the output gap. ${ }^{14}$ The displayed estimates were computed using a HP-based measure of inflation expectations and, alternatively, employing either STS or HP definitions of the output gap, as well as by substituting industrial production for output.

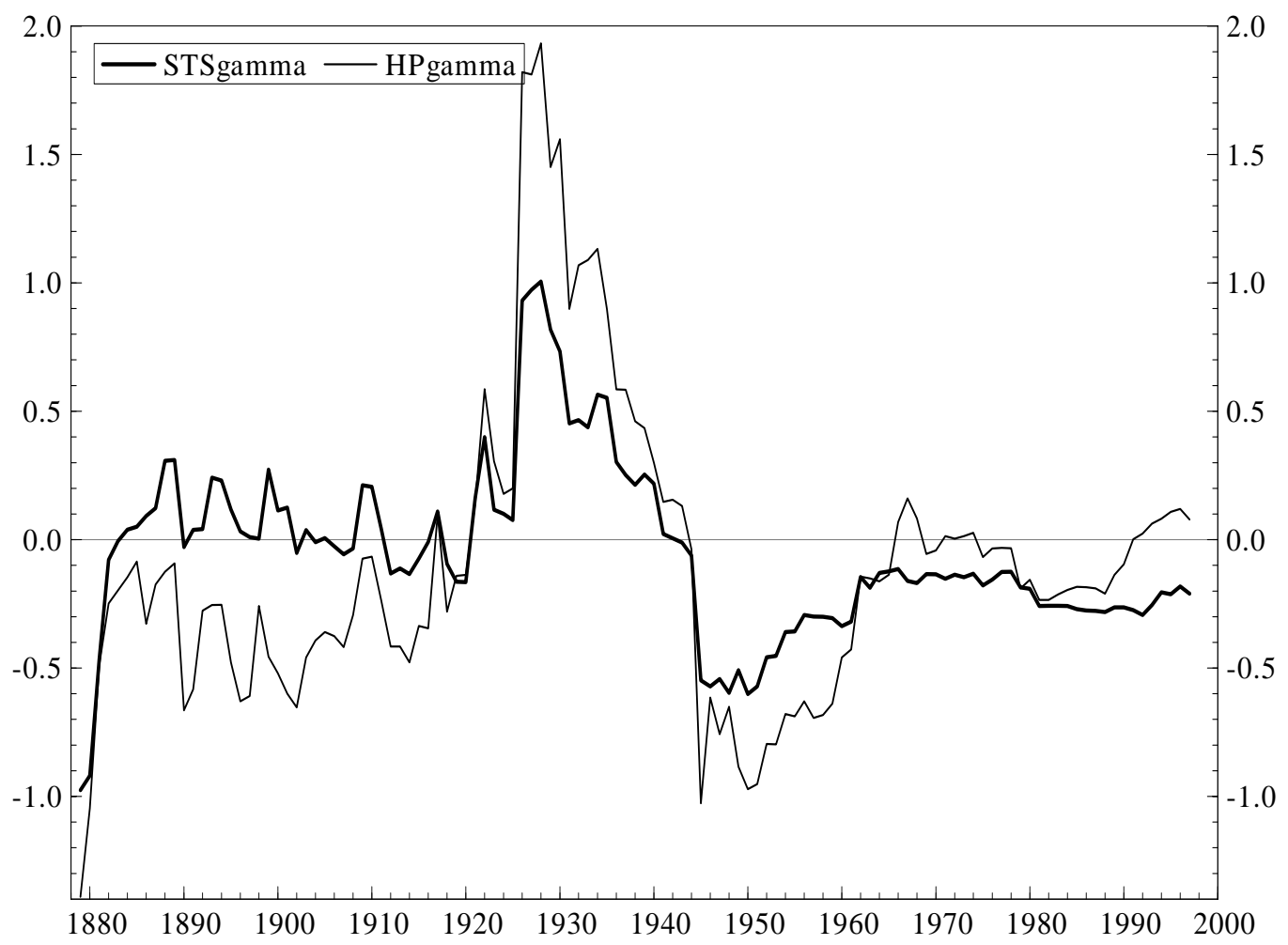

Figure 10: Time-varying coefficient of the output gap of the Italian Phillips curve, 1861-1998. HP and STS refer to the Hodrick-Prescott and STS-based measures of the output gap.

The graph confirms the dynamics of the link between inflation and output. The value of the estimated coefficient drops in periods of higher macroeconomic variability, regardless of the measure of the output gap employed. It becomes negative during

\footnotetext{
${ }^{14}$ For brevity we do not show here the full results of our TVP estimation (including those obtained using industrial production), which are available from the authors upon request.
} 
World War II, when the conventional Phillips curve breaks down.

\section{A comparison with the United States and the United Kingdom}

It behoves us now to compare our findings for Italy with those from other countries using the same methodology and same period. Therefore, we extended the analysis to the United States (USA) and the United Kingdom (UK). Figure 11 groups the annual inflation rates (based on the price deflator of national income) for the three countries. Italian inflation easily emerges as having the highest mean and volatility. ${ }^{15}$

Turning to a comparison of the inflation-output relationships across the three countries, Table 4 contains the results of the NKPC specification, equation (3), estimated with OLS, both for the whole sample and for the sub-samples of the international gold standard, the two world wars, and the post-1946 period. ${ }^{16}$

\footnotetext{
${ }^{15}$ Higher Italian mean and volatility of inflation also holds for sub-periods except one. Furthermore, Italian and UK inflation rates have similar persistence levels, both far higher than for the US.

${ }^{16}$ For these estimates, we measured real activity via either the output gap (HP-based series for potential output) or the log change in industrial production. As results do not qualitatively differ across specifications, we opted for presenting those based on output gaps.
} 


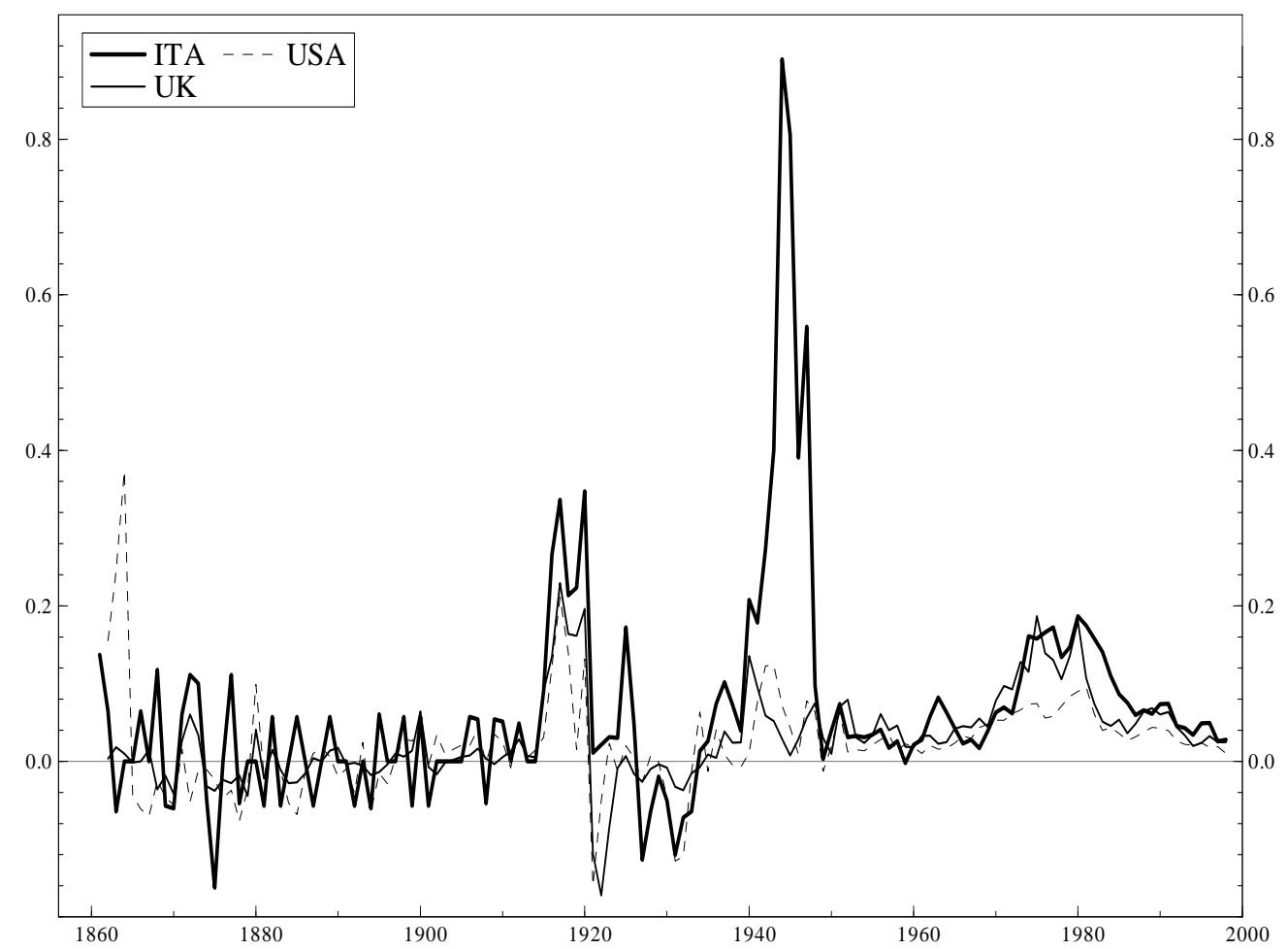

Figure 11: Inflation rates in Italy, USA, and UK, 1861-1998.

\begin{tabular}{|l|c|c|c|}
\hline \hline \multicolumn{4}{|c|}{ NKPC: USA } \\
\hline Sample & $E_{t} \pi_{t+1}$ & $\pi_{t-1}$ & $\left(y_{t}-y_{t}^{*}\right)$ \\
\hline \multirow{2}{*}{ 1861-1998 } & 1.031 & 0.167 & 0.069 \\
& $(7.16)$ & $(2.07)$ & $(1.08)$ \\
\hline \multirow{2}{*}{$\mathbf{1 8 6 1 - 1 9 1 3}$} & 1.274 & -0.042 & -0.215 \\
& $(4.52)$ & $(-0.28)$ & $(-1.48)$ \\
\hline \multirow{2}{*}{ 1914-1949 } & 1.285 & 0.000 & 0.218 \\
& $(3.83)$ & $(0.00)$ & $(1.94)$ \\
\hline \multirow{2}{*}{ 1950-1998 } & 0.707 & 0.302 & 0.127 \\
& $(6.02)$ & $(2.67)$ & $(2.16)$ \\
\hline \hline \multirow{4}{*}{ NKPC: UK } \\
\hline Sample & $E_{t} \pi_{t+1}$ & $\pi_{t-1}$ & $\left(y_{t}-y_{t}^{*}\right)$ \\
\hline \multirow{2}{*}{$\mathbf{1 8 6 1 - 1 9 9 8}$} & 0.639 & 0.397 & 0.356 \\
& $(7.04)$ & $(5.83)$ & $(4.62)$ \\
\hline 1861-1913 & 0.331 & 0.158 & 0.185 \\
\hline
\end{tabular}




\begin{tabular}{|l|c|c|c|}
\hline & $(1.76)$ & $(1.15)$ & $(1.87)$ \\
\hline \multirow{2}{*}{ 1914-1949 } & 0.763 & 0.390 & 0.463 \\
& $(2.93)$ & $(3.03)$ & $(2.79)$ \\
\hline \multirow{2}{*}{ 1950-1998 } & 0.649 & 0.369 & 0.179 \\
& $(4.90)$ & $(2.98)$ & $(1.36)$ \\
\hline \hline \multicolumn{3}{|c|}{ NKPC: Italy } \\
\hline \multirow{2}{*}{ Sample } & $E_{t} \pi_{t+1}$ & $\pi_{t-1}$ & $\left(y_{t}-y_{t}^{*}\right)$ \\
\hline \multirow{2}{*}{ 1861-1998 } & 0.981 & 0.079 & -0.881 \\
& $(11.00)$ & $(1.09)$ & $(-7.55)$ \\
\hline \multirow{2}{*}{ 1861-1913 } & 0.574 & -0.057 & -0.383 \\
& $(1.88)$ & $(-0.41)$ & $(-1.26)$ \\
\hline \multirow{2}{*}{ 1914-1949 } & 1.031 & 0.049 & -0.969 \\
& $(6.07)$ & $(0.36)$ & $(-4.48)$ \\
\hline \multirow{2}{*}{ 1950-1998 } & 0.369 & 0.630 & 0.023 \\
& $(3.63)$ & $(6.33)$ & $(0.178)$ \\
\hline
\end{tabular}

Table 4: New Keynesian Phillips Curve for Italy, USA, and UK, various samples. Coefficient estimates and t-values.

The main results can be summarized as follows:

1. Over the full sample, the output coefficient is statistically significant and positive only for the UK, and it is again negative for Italy;

2. Over the sub-samples, output is positively related to inflation in the USA in 1914-1949 and 1950-1998 and in the UK in all sub-periods until World War II;

3. Inflation expectations are always the fundamental determinants of actual inflation rates; and

4. The international gold standard stands out as the sub-period with the most ambiguous results.

Finally, to get a sense of the cross-country evolution of the inflation-output relationship, we also estimated TVP models for the USA and the UK. Figure 12 plots the output gap coefficients computed using the TVP methodology. The distinctive finding is that the UK and Italy share similar declines in the size of the output gap coefficient after WWII, although in the UK the long-run relationship seems to have held up. In the USA, the sensitivity of inflation to output developments is both more sizeable and stable, with no fundamental breaks even during the stagflation of 1970s. These 
findings broadly confirm in a cross-country dimension that the standard trade-off between inflation and output growth emerges only during periods of low inflation and limited macroeconomic volatility.

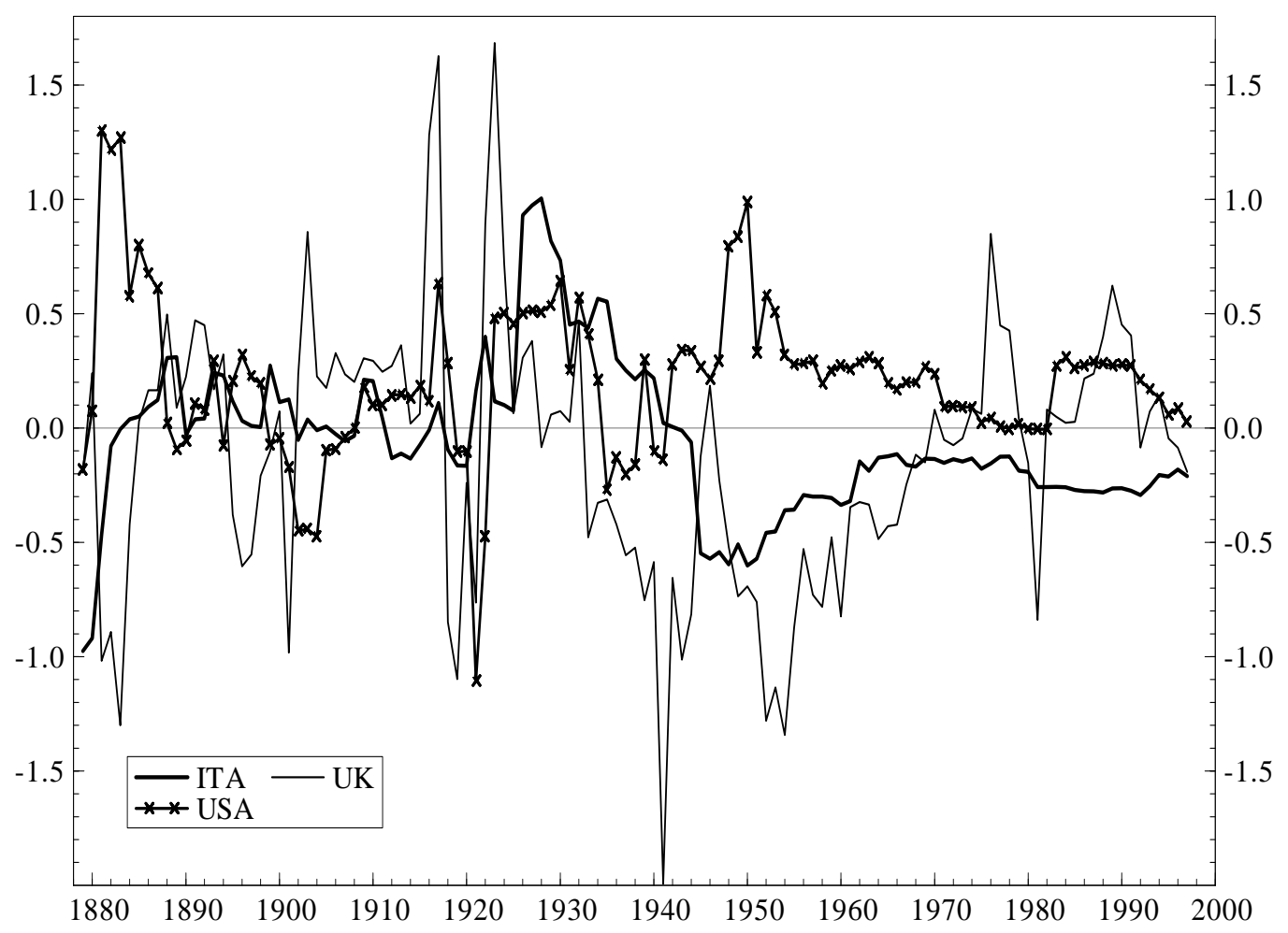

Figure 12: Time-varying coefficient of the output gap for Italy, USA, and UK, 1861-1998. TVP coefficients based on STS.

\section{Concluding remarks}

Rather than summarize once more the various findings of the paper, we emphasize two conclusions. The first relates to the distinctiveness of the Italian inflation rate, in the specific sense that it has been systematically higher and more variable than the inflation rates experienced elsewhere in the industrial world and specifically in the anglo-saxon countries. The key finding of our study is that the standard trade-off between inflation and output growth breaks down during periods of high inflation and marked macroeconomic volatility. It follows that the peculiar nature of the Italian output-inflation trade-off is in part the consequence of the comparative disadvantage 
of the Italian economy to withstand adverse supply-side shocks and in part the result of the poor quality of its monetary policy. This conclusion resonates well with a famous message by Lucas on the properties of the trade-off (1973, pp. 332-333):

"In a stable price country like the United States, then, policies which increase nominal income tend to have a large initial effect on real output, together with a small, positive initial effect on the rate of inflation. Thus, the apparent short-term trade-off is favorable, as long as it remains unused. In contrast, in a volatile price country like Argentina, nominal income changes are associated with equal, contemporaneous price movements with no discernible effect on real output. These results are, of course, inconsistent with the existence of even moderately stable Phillips curves. On the other hand, they follow directly from the view that inflation stimulates real output if, and only if, it succeeds in "fooling" suppliers of labor and goods into thinking relative prices are moving in their favour."

The second relates to the successful Italian disinflation of the 1990s, one that permitted the country to join the EMU. After an extraordinarily long period of time the country was finally able to tame inflation. The evidence marshalled in the paper is consistent with the received wisdom that Italy has reined in inflation thanks largely to global disinflation pressures and the establishment of an independent central bank in the 1990s. We leave it to future research the determination of which of these two factors played a dominant role in the taming of inflation. Regardless of their relative importance, the question comes to mind whether Italy can sustain a low-inflation regime in the absence of a friendly global environment and of an independent central bank. While there is a high probability that the European Central Bank may remain independent, the same cannot be said about the permanence of Italian membership in the EMU. 


\section{References}

Bai, J., and P. Perron (1998). Estimating and Testing Linear Models with Multiple Structural Changes, Econometrica, vol 66, 47-78.

Bai, J. and P. Perron (2003). Computation and Analysis of Multiple Structural Change Models, Journal of Applied Econometrics, 18, 1-22.

Canova, F. (2007). Methods for Applied Macroeconomic Research. Princeton University Press, Princeton.

Cecchetti, S.G., P. Hooper, B.C. Kasman, K.L. Schoenholtz, and M.W. Watson (2007). Understanding the evolving inflation process. U.S. Monetary Policy Forum 2007, University of Chicago Graduate School of Business, The Initiative on Global Financial Markets.

Doan, T., Litterman, R. and Sims, C. (1984). Forecasting and conditional projections using realist priori distributions. Econometric Reviews, 3(1), 1-100.

Doornik, J.A., and H. Hansen (1994). A practical test for univariate and multivariate normality. Discussion Paper, Nuffield College.

Flora, A. (1983). State, Economy and Society in Western Europe 1815-1975, vol. I, Campus: Frankfurt.

Flora, A. (1987). State, Economy and Society in Western Europe 1815-1975, vol. II, Campus: Frankfurt.

Fratianni, M. (1978), Inflation and and Unanticipated Changes in Ouput in Italy, Carnegie-Rochester Conference Series on Public Policy, 8:141-180.

Fratianni, M. and F., Spinelli (1981), Sylos Labini on Fratianni and Spinelli on Inflation: a Reply, Banca Nazionale del Lavoro Quarterly Review, 139: 466-469.

Fratianni, M. and F., Spinelli (2001a) Storia Monetaria d'Italia. Milan: EtasLibri, 2001.

Fratianni, M. and F., Spinelli (2001b) Fiscal Dominance and Money Growth in Italy: The Long Record, Explorations in Economic History, 38: 252-272.

Friedman, M. (1968). The role of monetary policy. American Economic Review, 58, pp. $1-17$.

Garofalo, P. (2005). Exchange Rate Regimes and Economic Performance: The Italian Experience. Banca d’Italia, Quaderni dell'Ufficio Ricerche Storiche, n. 10.

Granger, C.W.J. and T. Terasvirta, T. (1993). Modelling Non-Linear Economic Relationships. Oxford University Press. 
Jarque, C.M., and A.K. Bera (1987). A test for normality of observations and regression residuals. International Statistical Review, 55, 163-172.

Harvey, A.C. (1989). Forecasting, Structural Time Series Models and the Kalman Filter. Cambridge: CUP.

Hamilton, J.D. (1994). Time-series analysis. Princeton University Press, Princeton.

Kim, C.-J. and C.R. Nelson (1999). State-space models with regime switching. MIT Press, Cambridge Mass.

Kim, C.-J. and C.R. Nelson (2006). Estimation of a forward-looking monetary policy rule: A time-varying parameter model using ex post data. Journal of Monetary Economics, 53, pp. 1949-1966.

Koopman S.J., Harvey, A.C., Doornik, J.A. and Shephard, N. (2000). Stamp: Structural Time Series Analyser, Modeller and Predictor. London: Timberlake Consultants Press.

Lucas, R.E. (1973). Some International Evidence on Output-Inflation Tradeoffs. American Economic Review, Vol. 63, No. 3, pp. 326-334.

Lucas, R.E. (1980). Two Illustrations of the Quantity Theory of Money. American Economic Review, Vol. 70, No. 5, pp. 1005-1014.

MacKinnon, J.G. (1991). Critical values for cointegration tests. In Engle, R.F., and C.W.J. Granger (eds.), Long-run economic relationships, pp. 267-276. Oxford: OUP.

Maddala, G.S., and I.-M. Kim (1998). Unit Roots, Cointegration and Structural Change. Cambridge University Press.

Micheletti, S., e F. Spinelli (2001). Introduzione all'Inflazione Italiana: 1861-1998. Edizioni Ori Martin, Brescia.

Mitchell, D. (1992). International Historical Statistics: Europe 1750-1988. Macmillan: London.

Mitchell, D. (1993). International Historical Statistics: The Americas 1750-1988. Macmillan: London.

Phelps, E.S., Phillips Curves (1967). Expectations of Inflation and Optimal Unemployment over Time. Economica, New Series, Vol. 34, No. 135, pp. 254281. 
Phillips, A.W.H. (1958). The Relation between Unemployment and the Rate of Change of Money Wage Rates in the United Kingdom, 1861-1957. Economica, New Series, Vol. 25, No. 100, pp. 283-299

Spinelli, F. (1976). The determinants of price and wage inflation: the case of Italy, in M. Parkin and G. Zis (eds.), Inflation in open economies, Manchester University Press, Manchester, pp. 201-236.

Spinelli, F. (1976). Il dilemma inflazione-disoccupazione: una rilettura critica, Rivista Internazionale di Scienze Sociali, LXXXIV, IV-V, pp. 517-525.

Spinelli, F. (2000). I costi dell'instabilità dei prezzi e del cambio. Le analisi delle Relazioni Annuali della Banca d'Italia: 1894-1998, Angeli, Milano.

Spinelli, F. (1980). Ancora su inflazione e capacità produttiva: una risposta ad Onofri, in G. La Malfa e F. Spinelli, L'economia italiana verso gli anni '80. VI Rapporto CEEP, Franco Angeli, Milano, pp. 77-90.

Spinelli, F., and C. Trecroci. (2008). “A long-run perspective on the purchasing power of the lira, 1861-1998”. Forthcoming, Review of Economic Conditions in Italy.

Stock, J.H., and M.W. Watson (2007). Why Has U.S. Inflation Become Harder to Forecast? Journal of Money, Banking and Credit, Vol. 39, No. 1.

Woodford, M. (2003). Interest and Prices: Foundations of a Theory of Monetary Policy, Princeton University Press. 